Environment Conservation Journal 16 (SE) 247-250, 2015

ISSN 0972-3099 (Print) 2278-5124 (Online)

Abstracted and Indexed

\title{
Prediction and optimization weld nugget size in resistance spot welding in low carbon steel using design of experiments
}

\section{M.Oveisi}

Received:25.06.2015

Revised:28.07.2015

Accepted: 30.10 .2015

\begin{abstract}
In this study, experiments were designed on the basis of response surface method to determine the effects of current, time and electrode pressure on weld nugget diameter using the Design Expert software. The experimental results were employed to develop a mathematical model which is able to predict linear, quadratic and two-factor interactive effects of these parameters on weld nugget diameter of $\mathrm{St12}$ steel with $0.8 \mathrm{~mm}$ thickness. Adequacy of the model was checked with the help of scatter diagrams and analysis of variance (ANOVA). The predicted results indicated that increase in current and time at low and medium values increased the weld nugget diameter but at higher values due to interactive effects of parameters their increase caused a decrease in weld nugget diameter. Current increase at constant pressures had a similar effect on weld nugget diameter. The developed model was also used to maximize the weld nugget diameter using the above mentioned software. The optimization results showed that weld nugget diameter obtained a maximum value of about $5.80 \mathrm{~mm}$ at $10.64 \mathrm{KA}$ current, 9 cycles and 2 bar electrode pressure.
\end{abstract}

Keywords: Spot Welding, Design of Experiments, Response Surface, Design Expert Software_Introduction, weld nugget.

\section{Introduction}

Resistance spot welding is widely used in automotive industries because of high speed, easiness, good automation possibility [1]. In spite of these advantages, controlling this process is difficult and costs a lot for automobile industries to achieve high quality welds. to obtain welds with no defects all the process parameters must be selected optimally and optimal welding conditions must be kept constant. The weld button diameter is the most important parameter that determines the mechanical properties of a spot weld [2]. Bigger weld button diameter increases tensile - shear strength. Various industrial standards have recommended a minimum weld size for a given sheet thickness. For example AWS / SAE/ANSI [3] have recommended equation

$$
d=\sqrt{6 t}
$$

Where $\mathrm{d}$ and $\mathrm{t}$ are weld button diameter and sheet thickness, respectively. However, this criterion (sheetthickness) rule does not always yield sufficient strength. The purpose of this research is to obtain a model based on experimental data (regression function) that can correlate input par

Author's Address

Department of marine Engineering, Chabahar Maritime University,

E-mail: M.ovisi@cmu.ac.ir. parameters of current, time and electrode pressure to weld nugget diameter meaningfully. The response surface method (RSM) is one of the experimental designs strategy that is used for modeling and analysis of issues in which the desirable response is influenced by several variables. The target is modeling and optimizing of the response [4].

Nowadays, several methods are employed for modeling resistance spot welding process which includes statistical and non-statistical methods [5, 6].

Lin et al [7] studied resistance spot welding process of high strength steel. In their study; time, current, electrode force and diameter of electrode were selected that influence on button diameter quality. They modeled the process with Taguchi method and then genetic algorithm and neural network methods were used to optimize the response.

Yi lu et al in [8] examined the influence of effective parameter on button geometry in resistance spot welding process for galvanized sheets. In their research they used orthogonal array for modeling the process and analysis of variance for optimization. In spite of numerous studies a model based on experimental results to predict button diameter for St12 sheet is not reported. In this 
study, experimental work is done using design of experiments to develop a model to predict a real relationship between process parameters and weld button diameter. Precise determination of process parameters can reduce production waste, cost and improve production quality.

\section{Experimental procedure}

A $0.8 \mathrm{~mm}$ thick uncoated low carbon steel that is typically used in automobile industry was used for this study. Yield strength of this sheet steel was 180 MPa and its ultimate tensile strength was $330 \mathrm{MPa}$ according to the manufacturer. The chemical composition of the steel was Fe:0.0097N: $0.011 \mathrm{~S}$ : 0.0093P: $0.02 \mathrm{Cr}: 0.004 \mathrm{Mo}: 0.034 \mathrm{Ni}: 0.039 \mathrm{Al}$ : 0.032Si: $0.189 \mathrm{Mn}: 0.045 \mathrm{C}$.

Welds were made using a $120 \mathrm{KVA}$, AC pedestal resistance spot welder. All tests used class $2(\mathrm{Cu}-$ $\mathrm{Zr}-\mathrm{Cr}$ ) truncated electrodes with a tip face of diameter of $5 \mathrm{~mm}$. runs using one factor at a time technique were conducted and finally three treatments were designed according to table 1 .

Table 1: Welding parameters

\begin{tabular}{|c|c|c|c|c|}
\hline parameter & Unit & -1 & 0 & 1 \\
\hline current & {$[$ KA] } & 7 & 9 & 11 \\
\hline Time & [Cycle] & 7 & 9 & 11 \\
\hline pressure & [bar] & 2 & 2.5 & 3 \\
\hline
\end{tabular}

32 test welds were made based on the design of experiments matrix obtained from the Design Expert software. The tests were made randomly to eliminate systematic errors. Sheets with $0.8 \mathrm{~mm} \times 1 \mathrm{~mm} \times 50 \mathrm{~mm}$ dimension were welded (Fig $1)$.

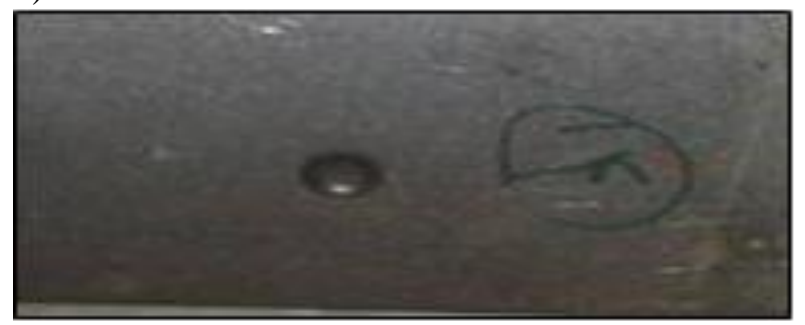

Figure1: sample welding

Using the results of these experiments and the Design Expert software a second order mathematical model (eq 2) was developed to predict the main, interaction and square effects of current, electrode pressure and welding time on weld $y=\beta_{0}+\sum_{j=1}^{k} \beta_{j} x_{j}+\sum_{i<j} \sum \beta_{i j} x_{i} x_{j}+\sum_{j=1}^{k} \beta_{j j} x_{j}{ }^{2}+\varepsilon$

In order to measure diameter of the resultant weld button; metallographic method was used. For this purpose the samples were prepared according to the standard and macrostructure of the samples were observed using optical microscope (fig. 2).

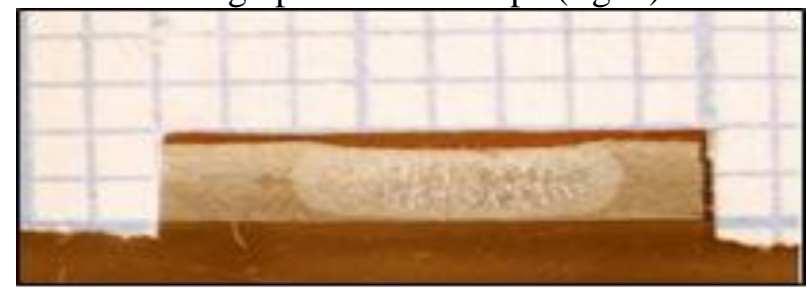

Figure 2: sample obtained under the microscope

\section{Results and discussions}

The analysis of variance obtained from the software and elimination of insignificant parameters led to the mathematical model presented below:

$D=5.16+.96 I+.44 t-.27 P-.59 I t-.15 I P-.66 I^{2}-.40 t^{2}$

Where $\mathrm{D}$ is weld button diameter in $\mathrm{mm}$ and $\mathrm{I}, \mathrm{P}$ and $t$ are process parameters in terms of coded values (table 1).

Adjustment of definition coefficient for the above model was calculated to be about 0.95

\section{Model validation}

There are two methods to check the model reliability.

1- Using scatter diagrams

2- Minimizing and maximizing the model variables

Fig. 3 shows the comparison of actual and predicted weld button diameters. also minimization and maximization of the model variables is shown in table 2. It seems that model in test range have a good behavior.

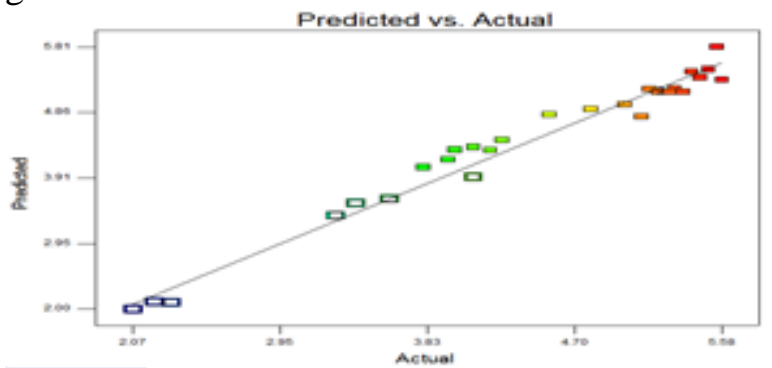

Figure3: Scatter diagram showing the actual values against the values obtained by the model 
Table 2: comparison of actual and predicted values

\begin{tabular}{|l|l|l|l|l|}
\hline $\begin{array}{l}\text { Predicted button } \\
\text { Diameter[mm] }\end{array}$ & $\begin{array}{l}\text { Actual button } \\
\text { diameter[mm] }\end{array}$ & Pressure [bar] & Time[cycle] & Current[KA] \\
\hline 2.24 & 2.06 & 2.8 & 7 & 7 \\
\hline 5.80 & 5.57 & 2 & 9 & 10.64 \\
\hline
\end{tabular}

\section{Studying the model behavior}

To achieve conditions that will result in the largest button diameter, three dimensional diagrams were used. It should be noted that studying the effect of one parameter alone (main effect) could be misleading due to interaction between process parameters.

a. Effect of current - time on weld button diameter

Fig. 4, shows the effect of weld current and time on weld button diameter at an electrode pressure of 2.5 bar, witnessing welding time and current increasing weld button diameter and the increased energy to the weld zone. Furthermore, the weld button diameter increased to maximum value with increase in welding time and then at higher levels $[9$ cycles and higher] the weld button diameter decreased. Heat input expulsion occurred at higher levels of time and current. Using higher level of current and lower level of welding time resulted in bigger weld button diameter.

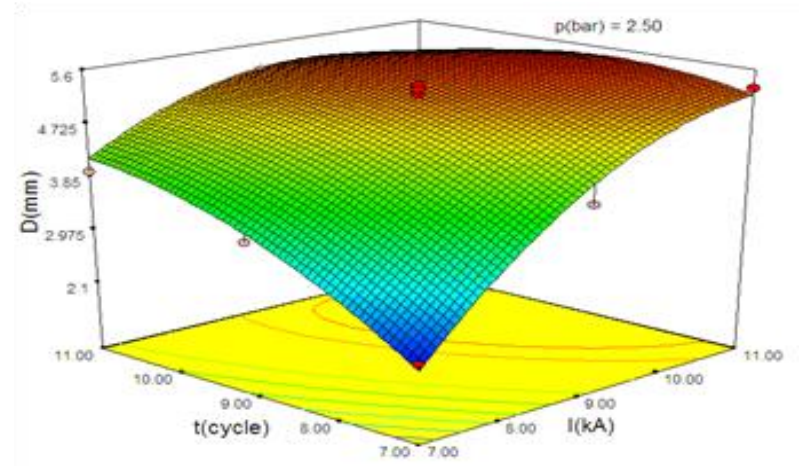

Figure 4: Variation of weld button diameter at $\mathbf{2 . 5}$ bar electrode pressure under different levels of current - time

Fig.5 shows variation of current and pressure at a constant welding time (11 cycles ). Increasing the current causes increase the weld button diameter and the maximum weld button diameter is obtained at highest current value. At constant levels of pressure and high levels of current, button diameter decreases and this phenomenon can be observed at higher levels of pressure due to excessive heat generated and the expulsion that occurred.

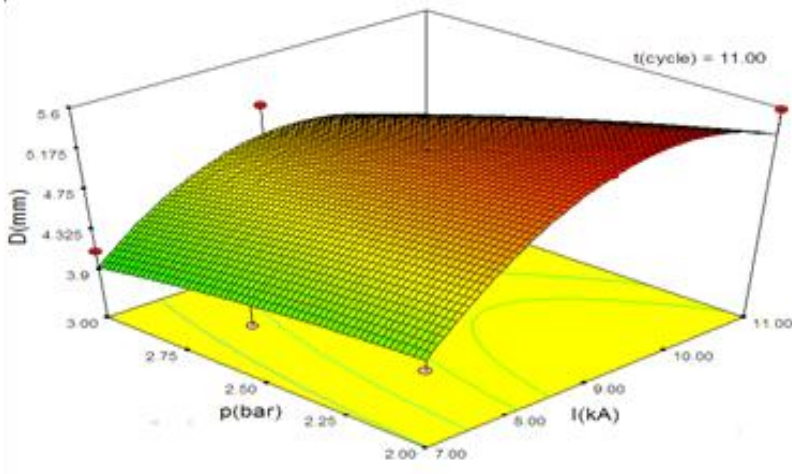

Figure 5: effect of current - pressure on weld button diameter in 11 time cycles

At the minimum level of welding time and pressure (fig. 6) the largest weld button diameter was obtained at the current of $11 \mathrm{kA}$ and minimum electrode force. but this maximum size is lower than nugget size results from fig 7 . With welding time of nine cycles (Fig. 7), the best condition of spot welding resulted and the largest spot weld was achieved at higher currents and lower pressures. With constant pressure and time, increasing the current increases the weld button diameter. The amount of weld button diameter decreased at high pressures due increase in the contact of sheets. For this reason the surface slope decreased at constant pressure.

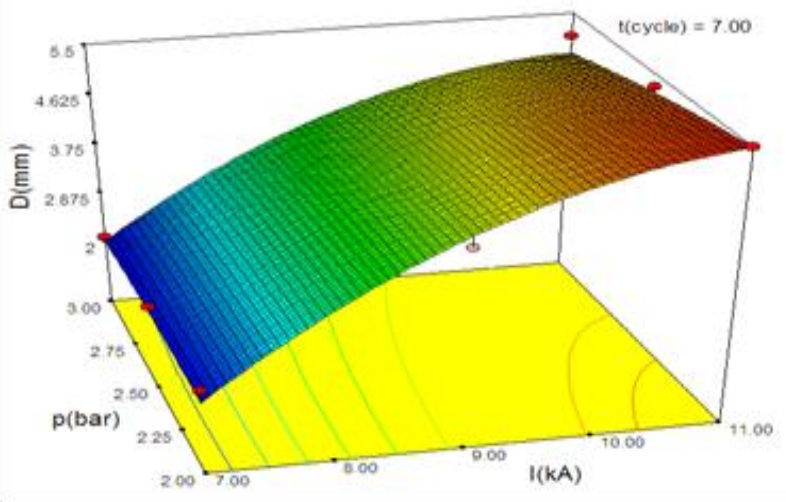

Figure 6: effect of current - pressure on weld button diameter in 7 time cycles 


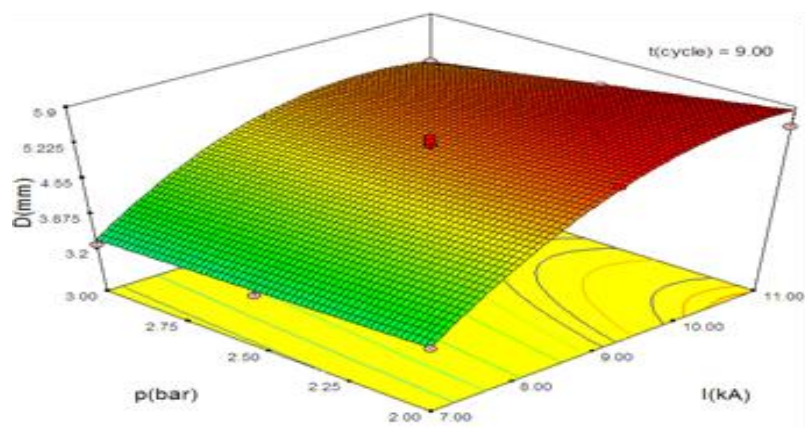

Figure7: effect of current - pressure on weld button diameter in 9 time cycles
It should be noted that largest weld button diameter was obtained under the above mentioned conditions due to the highest current.

\section{Optimization}

Considering that weld strength is a function of weld button diameter, to obtain maximum weld button diameter; values of current, time and electrode pressure must be optimized.

\begin{tabular}{|c|c|c|c|}
\hline Button diameter(mm) & Welding current(KA) & Time(cycle) & Electrode pressure(bar) \\
\hline 5.80 & 10.64 & 9 & 2 \\
\hline 5.80 & 19.91 & 8.91 & 2 \\
\hline 5.80 & 9.51 & 10.30 & 2 \\
\hline
\end{tabular}

Table 3: Optimized results

According to table 3, under various conditions of current, time and electrode pressure maximum weld nugget diameter can be achieved. Welding speed in resistance spot welding is an important consideration; therefore minimum time should be selected from the above table and current and electrode pressure ought to be set accordingly to obtain a weld button diameter of $5.8 \mathrm{~mm}$ diameter.

\section{References}

Chao, J., Morkey N. 2003. Ultimate Strength and Failure Mechanism of Resistance Spot Weld Subjected to Tensile, or combined Tensile/Shear Loads, Journal of Engineering Materials and Technology 25:125-133

Pouranvari, M., Asgari, H.A., Marashi, M.H., Goodarzi, M. 2003. Effect of weld nugget size on overload failure mode of resistance spot welds in : Journal of Science and Technology of Welding and Joining 2: 223-231.

American Welding Society 1997. Recommended practices for test methods for evaluating the resistance spot Welding Behavior of Automotive Sheet Steel Materials, ANSI/AWS/SAE/D8.9-97.

Khuri, A., Cornell, J. A. 1996. Response Surfaces Design and Analysis, Marcel Dekker, 2nd edition, New York.

\section{Conclusion}

1- The obtained definition coefficient indicates weld button diameter is influenced by the process parameters and the process is controllable.

2- Current has more effect on nugget diameter than time and electrode pressure.

3- At high welding cycles and currents smaller weld button diameter was obtained.

4- The maximum weld button diameter was obtained at a current of 10-11 kA and 9 cycle time at lower pressure.

Cho, J. A., Li, W., Hu, S. J. 2007. Design of Experiment Analysis and Weld Lobe Estimation for Aluminum Resistance Spot Welding, Welding Journal 9: 45-51.

Han, Y., Byeong, M., Li, K., H., Park, Y. K. 2009. Strength Characteristics on Resistance Spot Welding of Al Alloy Sheets by Taguchi Method, International Journal of Modern 20:42974320.

Lin, L., T., Chou, Chou, C. P. 2008. Modelling and optimization of the Resistance Spot Welding Process via a Taguchi-Neural Approach in The Automobile Industry.

Yi, Luo., Hong, Ye., Xiong, Cheng Zhi., Lin, Xu. 2009.Resistance Spot Welding Process of Galvanized Steel Sheet Based on Regression Modeling, Jounal of Material Science Forum 610:681-689. 